\title{
Ricardo Palma en el amanecer republicano'
}

\author{
Luis Alberto Arista Montoya. \\ Instituto de Investigaciones de la Escuela de Turismo \\ de la Universidad de San Martín de Porres. \\ luisalbertoarista@gmail.com \\ Lima-Perú
}

\section{Resumen}

Este artículo explora la perspectiva histórica de Ricardo Palma a través de sus tradiciones sobre los avatares de la lucha por el nuevo poder generado por facciones civiles y militares de la clase política criolla en el contexto de la Emancipación. Algunas de las tradiciones políticas de Palma sobre la tensa transición de la época colonial hacia la época democrática republicana son documentos claves para comprender el nuevo tiempo histórico fundacional. Ese amanecer republicano tuvo muchas más sombras que luces.

Palabras clave: Tradición, colonia, Emancipación, nuevo mundo, clase criolla, poder.

\section{Abstract}

The present article explains Ricardo Palma's historical perspective through his traditions related to the ups and downs of the fight for the new power generated by civil and military factions of the criolla political class in the Emancipation context. Some of Palma's political traditions about the difficult transition from the colonial era to the democratic republican era are key documents for understanding the new historical time. There were many more shadows than lights in that Emancipation.

Keywords: Tradition, colony, Emancipation, new world, criolla class, power.

I El presente ensayo es parte de un capítulo de mi libro La temporalidad histórica de la ironía en las Tradiciones de Don Ricardo Palma, próximo a ser publicado por la Universidad Ricardo Palma. 


\section{Luis Alberto Arista Montoya (Perú)}

Profesor universitario de Filosofía y Ciencias Sociales. Labora como profesor investigador de la Escuela de Turismo en la Universidad de San Martín de Porres. Premio Nacional de Investigación CONCYTEC-1989, por su trabajo La socialización de los niños en una cultura de violencia; Premio OEA en Ensayo por su trabajo «Los niños de familias de clase media y los imperativos sistémicos» (México-2004). Ejerció el cargo de director del diario Oficial El Peruano (1995-1996), y de director Nacional del Instituto Nacional de Cultura de Perú-INC (1996-1999). Autor de Existencialismo y Marxismo en el Pensamiento de Sartre (1984); Ortega y Gasset, pensador de la crisis (1993); J. Habermas: comunicación, modernidad y consenso (2004), etc. 
«Sabido es que para los habitantes de la republicana Lima las cuestiones de fueros y regalías entre los poderes civil y eclesiásticos han sido siempre una piedrecilla de escándalo. Aun los que hemos nacido en estos asendereados tiempos recordamos muchas enguinfingalfas entre nuestros presidentes y el metropolitano o los obispos. Mas en la época en que por su majestad don Fernando VI mandaba estos reinos del Perú el señor conde de Superunda estaban casi contrabalanceados los dos poderes y harto tímido era su excelencia para recurrir a golpes de autoridad».

Ricardo Palma. «Un virrey y un arzobispo», crónica de la época (1745-1761) del virrey José Manso de Velasco, conde de Superunda.

En Tradiciones Peruanas, tomo 2; p. 112.

«Aquellos comienzos del año 1833 en que el Perú vio nacer, en su capital poética, al más representativo de sus literatos, hijo señero de Lima, fueron para la incipiente república, de peligrosa turbulencia política, que continuaría, durante no corto periodo, en fatal progresión».

Angélica Palma. En Palma, p. 7.

\section{Introducción}

Debe partirse aclarando antes la idea de «época fundacional de la República», un concepto de orden historicista. ¿Cuándo empieza a gestarse el proyecto de fundación de la República peruana? ¿Qué se entiende por época fundacional? ¿Quiénes fueron los actores involucrados? ¿Significó el ocaso y fenecimiento de la época colonial? ¿Cómo se perfilaron las nuevas instituciones republicanas? ¿Cuál fue el rol de los intelectuales? 
Indudablemente fue un cambio de época que no necesariamente significó un cambio de ideas y creencias, un cambio de mentalidad, aunque cundió - en ciertos sectores sociales liberales - un gran entusiasmo revolucionario pero temeroso, al mismo tiempo, por lo que advenía en forma violenta.

Con la proclamación de la Independencia Política del Perú respecto al Imperio español, representado a través de la administración política de 38 virreyes (representantes de facto de la monarquía española), se produce el azaroso punto de partida oficial del régimen republicano. Mas no fue un definitivo punto de quiebre, porque el país siguió portando muchas instituciones y comportamientos coloniales (que han permanecido hasta hoy como una impronta que ha troquelado la memoria de los gobernantes republicanos y de la burocracia oficial del Estado).

El «mundo de vida» colonial y colonizador siguió vigente directa o soterradamente, porque el «mundo sistémico» (administrativo, legal, laboral, financiero) estructurado desde la metrópoli española persistía en mantener su poder a través de nuevos actores (criollos colaboradores, mestizos acriollados, esclavos, intelectuales, funcionarios, militares).

«Los grupos de criollos conquistaron la independencia del Perú sin abjurar del todo de la colonia», según el historiador Pablo Macera (2014). Los actores peruanos de la ideología republicana en esa época inicial se mantuvieron, eso sí, en estado de alerta, en una acción comunicativa de carácter reformador (la acción pedagógica del precursor Toribio Rodríguez de Mendoza es un ejemplo de ello), muchos otros se mantuvieron indiferentes y otros enfrentados, disputándose las granjerías del poder en la naciente República peruana. 


\section{Prolegómenos}

Los prolegómenos de la época fundacional empezaron desde mucho antes de 1821. Brotaron una serie de rebeliones y revueltas independentistas en varias regiones.

«La primera gran rebelión indígena acaeció, pues, en la selva peruana acaudillada por Juan Santos Atawalpa en 1742 [quien] durante 14 años mantuvo una victoriosa resistencia» (Valcárcel, 2014, p. 135); la cual repercute en «la insurrección de Francisco Inca, con ramificaciones en Lima, que fracasó por traición de algunos comprometidos» (ibíd.); en 1814 se produjo la rebelión cusqueña encabezada por José Angulo, sus hermanos, el cacique Pumacawa y el canónigo español Francisco Carrascón. Esta rebelión cusqueña fue el último gran intento propio para emancipar el Perú.

En Tacna, Jaén, Chachapoyas y otras ciudades también se produjeron sendos movimientos libertarios, que fueron estudiados por el historiador Jorge Basadre, quien precisamente denomina a este primer periodo «La Época Fundacional de la República» (1822-1842). Es en esta etapa que se produce la definición y crítica del ideario constitucionalista y de la realidad en la vida nacional e internacional del Perú, entre 1822 y 1829 ; también se da el primer ciclo de la Época Fundacional de la República, que involucró la Determinación Nacional durante la Guerra Emancipadora (1821-1825); y, entre 1822-1825, «el choque entre el mundo de las ideas imperantes en el Congreso Constituyente y el mundo de los hechos» (Basadre, 1983, p. I y ss.).

La revolución indígena acaudillada por el cacique José Gabriel Túpac Amaru y su esposa Micaela Bastidas empezó el 4 de noviembre de 1780 y fue brutalmente reprimida. El 18 de mayo de 1781, Túpac Amaru, su esposa, dos de sus hijos y sus 
principales capitanes fueron ajusticiados en la plaza del Cusco. Diego Cristóbal Túpac Amaru, su lugarteniente, tomó el mando (entre 1781-1783) con el fin de rescatar a Túpac Amaru, mas no lo logró (Valcárcel, 1985, pp.128-132).

Véase al respecto la tradición «El resucitado», ambientada en la época del trigésimo segundo virrey del Perú, Manuel Guirior (1776-1780), donde Palma se refiere a la gesta emancipadora de Túpac Amaru. En ella se narra cómo el virrey Guirior salió victorioso en el juicio de residencia que se le siguió en España durante el reinado de Carlos III; mientras que el sanguinario visitador y superintendente José de Areche «fue castigado severamente» (1996, pp. 137-138).

Pese a su cruento sofocamiento, la revolución de Túpac Amaru impactó en toda Sudamérica y en el gran movimiento militarista que se dio posteriormente bajo el liderazgo de dos militares extranjeros: José de San Martín y Simón Bolívar. (Dicho sea de paso, dada la proximidad de la conmemoración del Bicentenario, se viene produciendo una interesante controversia entre algunos nuevos historiadores sobre la épica de San Martín versus la épica de Simón Bolívar, que de alguna manera están animando el ambiente académico, no obstante los estragos de la pandemia de la covid-19).

\section{Posición republicana}

El cronista y tradicionista Ricardo Palma nació el 7 de febrero de 1833, doce años después de la fundación oficial de la República independiente peruana. Por tanto, todo el primer trecho generacional y vital de su trayectoria (el lapso de tiempo durante sus primeros 15 años de edad) estuvo signado por un tiempo-histórico-tensional causado por el cambio entre una época colonial, que resistía al cambio, y una inaugural nueva época 
republicana, que buscaba derruir las instituciones del ancien régime proponiendo instituciones democráticas, republicanas que se abrieron paso con muchísima dificultad, produciéndose un desacoplamiento social entre las nuevas generaciones (de niños y jóvenes) y la generación adulta que mostraba visos de rebeldía, en muchos casos, pero todavía dentro de una adaptación y asimilación de las costumbres coloniales supérstites.

De niño y adolescente, Ricardo Palma vivió y padeció ese desacoplamiento social, no tanto en su hogar, pero sí en la escuela, en la calle y en su comunidad. Con ojos de buen ver, el niño Ricardo miraba y registraba en su memoria esta física y metafísica de las costumbres. Es por eso que a partir de los 15 años de edad empieza a escribir en periódicos y revistas, donde pergeña algunas crónicas que luego se convertirían en las llamadas Tradiciones Peruanas (12 tomos), una especie de gran mural histórico de esa época de transición entre el tiempo histórico del fenecimiento lento de la Colonia y el advenimiento también lento, pero lleno de violencia, del tiempo histórico republicano.

Palma no registró esta transición desde la racionalidad científica propia de un historiador, sino desde una racionalidad irónica, es decir, con humor, gracia, sátira y burla, bajo una visión crítica de una sociedad que portaba una democracia incierta todavía e inconclusa como la padecemos actualmente (agosto, 2020). Es por eso que algunos teóricos (y políticos) proponen re-fundar la República a partir del 2021 (¿Cómo? ¿Quiénes? ¿Cuándo? ¿Sin consenso?). Toda una utopía política.

Mientras tanto, invito a realizar en las universidades una translectura (interdisciplinaria, cruzada) de las Tradiciones Peruanas de Don Ricardo Palma, en homenaje a su obraje (al conjunto indesligable de su vida/obra), declarada en 2018 Patrimonio Cultural de la Nación por el Ministerio de Cultura del Perú. 


\section{Primeras referencias}

Narra Palma:

Que en ciertas noches la plazuela de San Agustín era invadida por una procesión de ánimas del purgatorio con cirio en mano. Yo [su «yo hermenéutico»] ni quito ni pongo; pero sospecho que con la República y el gas [se refiere a la luz del gas] les hemos metido el resuello a las ánimas benditas, que se están muy mohínas y quietas en el siglo donde a su Divina Majestad plugo ponerlas (1996, p. 100).

Esta costumbre nocturna de miedo social se mantuvo hasta bien iniciada la República, pese al alumbrado público de las farolas de gas y a las rondas de los serenos. Esta es la primera referencia que hace Palma a los inicios de la República incipiente.

Más adelante, en una crónica de la época del conde de Superunda, Palma dice fehacientemente que «la época del coloniaje, fecunda en acontecimientos que de una manera providencial fueron preparando el día de la Independencia del Nuevo Mundo, es un venero poco explotado aun por las inteligencias americanas» (p. 107). Es decir, es en el mundo de la vida colonial donde van gestándose las contradicciones que van a dar paso al nuevo mundo sistémico republicano (mundo que hasta ahora porta muchos hábitos y costumbres propios de la época colonial, como el desequilibrio de poderes, la corrupción administrativa, el ejercicio del poder por estancos, el caudillismo, el autoritarismo, el racismo, los prejuicios religiosos, el maltrato a los indios y nativos de la selva, etc.).

El conde de Superunda, en su relación de mando, dice, hablando del arzobispo: Tuvo la desgracia de encontrar genios de fuego conocidos por turbulentos y capaces de alterar la república más bien ordenada. Estos [llamados 
asesores, hogaño] le indujeron a mandar sin reflexión persuadiéndolo que debía mandar su jurisdicción con vigor [autoritarismo] y que ésta se extendía sin límite. Y como obraba sin experiencia, brevemente se llenó de tropiezos con su Cabildo y varios tribunales (ibíd., pp. 112-113).

Y sobre la frustrada rebelión de Huarochirí comandada por el rebelde indio Apu Inca, Palma dice en la tradición «Un virrey y un arzobispo», de la época del virrey Manso de Velasco, conde de Superunda:

No se nos tilde de faltos de amor a la causa americana porque llamamos rebelde a Apu Inca. Las naciones se hallan siempre dispuestas a recibir el bienhechor rocío de la libertad, y en nuestro concepto, dando fe a documentos que hemos podido consultar, Apu Inca no era ni el apóstol de la idea redentora ni el descendiente de Manco Cápac. Sus pretensiones eran las del ambicioso sin talento, que, usurpando un nombre se convierte en jefe de una horda. Él proclamaba el exterminio de la raza blanca, sin ofrecer al indígena de su rehabilitación política. Su causa era la de la barbarie contra la civilización (p. 120).

Confróntese lo que dice Palma sobre la rebelión de Apu Inca en Huarochirí con lo que posteriormente se sabe de ella gracias a la recopilación de narraciones quechuas hechas (posiblemente en 1598) por Francisco de Ávila y registradas en el capítulo 23 del libro Dioses y Hombres de Huarochirí (2012).

Cuestión de antiguas costumbres. Sí. En una crónica de la época del virrey Amat y en referencia a los constantes robos de aquellos años, Palma nos dice:

Por los años de 1772, los habitantes de esta hoy prácticamente republicana ciudad de los Reyes se hallaban poseídos del más profundo pánico [...]. Una carrera de 
gatos o ratones en el techo bastante para producir en una casa soponcios femeniles, alarmas masculinas y barullópolis mayúsculo.

La situación no era para menos. Cada dos o tres noches se realizaba algún robo de magnitud, y según los cronistas de esos tiempos, tales delitos salían, en la forma, de las prácticas hasta entonces usadas por los discípulos de Caco (p. 130).

Al poder político generado por los corruptos de hogaño, seguidores de Caco, el filósofo peruano Edgar Montiel lo denomina «Cacocracia».

La idea de la cita anterior que merece resaltar es la de «prácticamente republicana ciudad», por el supérstite problema incluso hasta nuestros días (agosto 2020, en plena pandemia) de la delincuencia urbana, de asaltos a humildes casas y grandes residencias.

En la crónica «El Resucitado», Palma refiere que en la época del virrey Manuel Guirior «se erigió el virreinato de Buenos Aires y quedó terminada la demarcación de límites del Perú, según el tratado de 1777 entre España y Portugal, tratado que después nos ha traído algunas desazones con el Brasil y el Ecuador» (p. 137), que a futuro abrieron límites y conflictos republicanos, como ahora nos consta, felizmente subsanados. «En el mismo aciago año de los tres sietes — continúa Palma - nos envió la corte al consejero de Indias don José de Areche», quien con su implacable política de tributo indígena terminó de «exprimir la naranja hasta dejarla sin jugo», creando condiciones objetivas y subjetivas para que, posteriormente (1780), se produjera el desembalse de la ira indígena colectiva: la revolución de Túpac Amaru. 
Durante el gobierno de Agustín de Jáuregui se produjo la muerte dada en los Andes

Al corregidor Arriaga, y con ella de que en una extensión de más de trescientas leguas era proclamado por Inca y soberano del Perú el cacique Túpac Amaru. No es del caso historiar aquí esta tremenda revolución que, como es sabido, puso en grave peligro al gobierno colonial. Poquísimo faltó para que entonces hubiese quedado realizada la obra de la Independencia (pp. 144-145).

«Además en 1779 se declaró la guerra entre España e Inglaterra» (p. 144); asimismo, los filibusteros asediaban el Pacífico.

Uno de los mejores actos del virrey Francisco Gil de Taboada, según Palma fue

el entusiasta apoyo que prestó a las letras. En $1^{\circ}$ de octubre de 1792 salía a la luz bajo el título de Diario Erudito la primera hoja de este carácter que hemos tenido, y poco tiempo después se fundaba el famoso Mercurio Peruano. En 1793 D. Hipólito Unanue, costeando el Estado la impresión, daba a la estampa la Guía de forasteros, que continuó en los años siguientes, libros llenos de curiosos datos, muy apreciados hoy por los que nos consagramos al estudio de los tiempos coloniales [temporalidad colonial]. El poeta de las adivinanzas, D. Esteban de Terralla y Landa, colaboraba activamente en el Diario de Lima; y el padre Diego Cisneros (que dio su nombre a la calle llamada hoy del padre Jerónimo), ilustradísimo sacerdote español, desterrado de Madrid por lo avanzado de sus ideas políticas, daba a conocer en un pequeño círculo de amigos íntimos [entre ellos se encontraba el ilustrado insurgente, el sacerdote chachapoyano Toribio Rodríguez de Mendoza] las obras de los enciclopedistas. El padre jeronimita sembraba la 
semilla que en un cuarto de siglo más tarde dio por fruto la República. Los padres Narciso Girval y Barceló y Manuel Sobreviela, evangélicos misioneros, enviaron al Mercurio Peruano notables descripciones y mapas importantes de las montañas [ceja de selva norte y centro]. En nuestra época son estos trabajos consultados con avidez, siempre que se pone sobre el tapete alguna cuestión de límites (pp. 164165) [negritas y agregados nuestros].

De la cita anterior resaltamos también el hincapié de Palma sobre su apego a documentos históricos.

\section{La suerte estaba echada}

Cuando el virrey Abascal se encontraba en «lucha abierta con los miembros del Cabildo y el alto clero» (pp. 190-191), se vio precisado a sofocar una sublevación del regimiento de Extremadura en la plaza Santa Catalina; su presencia y energía, más las cuerdas de cáñamo que portaba en mano «para colgar racimos humanos en la horca», restablecieron el orden.

Realizada por entonces la Independencia de algunas repúblicas americanas, la idea de libertad hacía también su camino en el Perú. Abascal había sofocado la revolución en Tacna y en el Cuzco, y sus refuerzos, por el momento, se consagraban vencerla en el alto Perú. Mientras él permaneciese al frente del poder, juzgaban los patriotas de Lima que era casi imposible salir avante (p. 191) [negritas nuestras].

Invadida España por las huestes de Napoleón,

[...] con la prisión del rey se había perdido el centro de gravedad en la vasta monarquía de Fernando VII; y las provincias americanas, aunque tímidamente aún, 
comenzaban a manifestar sus deseos de separarse de una corona que moralmente no existía ya (p. 193).

El anhelo general en Lima «era la independencia bajo el reinado de Abascal. Nobleza, clero, ejército y pueblo lo deseaban y lo esperaban» (ibíd.). Pero «el 7 de julio de 1816 entregó el mando a su favorito don Joaquín de la Pezuela» (p. 192).

Abascal escribió las proféticas palabras en una carta dirigida a uno de sus amigos. La suerte estaba echada.

Harto he hecho por atajar el torrente, y no quiero, ante la Historia y ante mi rey, cargar con la responsabilidad de que el Perú se pierda para España entre mis manos. Tal vez otro logre lo que yo no me siento con la fuerzas para alcanzar (ibíd.).

\section{«Ollas contrabandistas»}

Apelando, a lo que denominamos el recurso del yo hermenéutico, Palma dice respecto del insurgente santo y seña «Con días y ollas venceremos», lo siguiente:

Eso es de lo que me propongo hoy hablar; apoyando mi relato, más que en la tradición oral que he oído contar al amanuense de San Martín y a otros soldados de la patria vieja, en la autoridad de mi amigo el escritor bonaerense D. Mariano Pelliza, que a vuela pluma se ocupa del santo y seña en uno de sus interesantes libros. (p. 205) [negritas nuestras].

Esta tradición es clave. Escribe Palma:

A principios de junio de 1821 , y cuando acababan de iniciarse las famosas negociaciones o armisticio de Punchauca [hacienda situada a las afueras de Lima norte] 
entre el virrey Laserna y el general San Martín, recibió el ejército patriota, acantonado en Huaura, el siguiente santo, seña y contraseña: Con-días-y-ollas-venceremos (ibíd.).

Actualmente la vieja casona de Punchauca pertenece al distrito limeño San Pedro de Carabayllo, está en total abandono por incuria del Ministerio de Cultura, un atentado contra la memoria histórica y el Patrimonio Arquitectónico de la nación peruana; su restauración sería un buen homenaje en conmemoración del Bicentenario.

Escribe Palma:

Para todos, exceptuando Monteagudo, Luzuriaga, Guido y García del Río, el santo y seña era una charada estúpida, una frase disparatada; y los que juzgaban a San Martín más cristiana y caritativamente se alzaban de hombros murmurando: «iExtravagancias del general!» (ibíd.).

Los mensajes políticos se enviaban por escrito desde Huaura a Lima utilizando ollas de doble fondo para evitar que los espías realistas los descubrieran. Pues «San Martín, por juiciosas razones que la historia consigna y aplaude, no quería deber la ocupación de Lima al éxito de una batalla, sino a los manejos y ardides de la política» (ibíd.).

Después de una serie de sospechas y acciones sobre las «ollas contrabandistas», al amanecer del día 6 de julio de 1821 «abandonaba el virrey Laserna la ciudad, de la cual tomaron posesión los patriotas en la noche del 9» (p. 212). 


\section{Corolario}

Palma finaliza su tradición así:

La victoria codiciada por San Martín era apoderarse de Lima sin quemar pólvora; y merced a las ollas que llevaban en el vientre ideas más formidables siempre que los cañones modernos, el éxito fue tan espléndido, que el 28 de julio se juraba en Lima la Independencia y se declaraba la autonomía del Perú. Junín y Ayacucho fueron el corolario (ibíd.).

Luego se produjo la batalla de Ayacucho, corolario de las gestas bélicas para la consumación independentista.

Plantear la batalla de Ayacucho como la culminación de nuestro ciclo libertario que compartimos con las repúblicas hermanas que ayudaron a desbaratar «el nudo del imperio», tiene muchísimo sentido. Por ser un virreinato importante —una de las joyas de la corona española - nuestra independencia pasó por una serie de fases y si se le compara a la de nuestros vecinos fue bastante tardía. (Mc Evoy, 2019, párr. 2)

\section{De la conciencia nacional}

El historiador Pablo Macera nos habla además de las tres etapas fundamentales en el desarrollo de la conciencia nacional: la etapa inicial y el desarrollo de la burguesía en el Perú, la etapa de la acción comunicativa de los Amantes del País en la Revista Mercurio Peruano y la etapa del liberalismo, a partir de la Constitución de Cádiz y la conciencia de patria.

En su introducción Macera escribe:

La mayoría de las historias de la revolución independiente americana han insistido en la pobre contribución del Perú 
a su propia independencia. Casi hemos sido considerados como españoles forzadamente llevados a la libertad. Este desprecio por la obra peruana es debido no solo al disculpable exclusivismo nacional de los historiadores extranjeros, sino también a nuestra actitud respecto a la etapa de la emancipación. Nuestros primeros historiadores de ella cronológicamente, Paz Soldán, Nemesio Vargas, se preocuparon con preferencia de los acontecimientos militares y políticos externos, en los que la intervención peruana, aunque definitiva, careció de personalidades como las extranjeras. Si no podemos llamar a la emancipación empresa extranjera es por obra del hombre común que sufraga los gastos de las luchas [protagonistas en las tradiciones de Palma] y por los doctrineros ideólogos [como Toribio Rodríguez de Mendoza, considerado como uno de los más importantes precursores de la Emancipación] que proveyeron de fe y entusiasmo a la tropa peruana revolucionaria.

Sin embargo, la opinión, en cuya formación han intervenido poquísimo los intelectuales peruanos republicanos, no lo ha entendido así; se ha negado a sí misma un antecedente justificativo de muchas de sus esperanzas actuales. En todas las ciudades peruanas hay una calle, escuela o plazuela, siempre la más destacada, en homenaje a la contribución extranjera; casi no existen, en cambio, o son adornos de suburbios, recuerdos de los miembros de la generación del Mercurio Peruano, de los liberales de 1832 o de los de nuestra primera Constituyente. De no deberse a la ignorancia y el descuido, podría atribuirse esa y otras actitudes al deseo interesado de estimular una psicología de resignación y pasividad de la que no estamos muy lejos ni carecemos de razones sociológicas para tener (2014, pp. 23-24).

Y sobre Palma, Macera dice brevemente que también don Ricardo se ocupó del autor de Voto Consultivo, obra de Pedro 
Joseph Bravo de Lagunas y Castillo ofrecida al virrey Antonio Manso de Velasco, conde de Superunda, dedicándole un recatado elogio en su estudio sobre las plañideras (p. 109). Palma también se refiere a esa obra en dos de sus tradiciones: «Castigo de un traidor» $\mathrm{y}$ «El divorcio de la condesita». La primera trata sobre la sublevación de los indios en 1750, donde Bravo de Lagunas intervino entonces para juzgar a los culpables. La segunda se refiere al célebre caso entre doña Mariana Belzunce y su frustrado marido, el anciano conde de Casa de Dávalos.

Cabe mencionar que Bravo de Lagunas fue autor de otras obras jurídicas como su Colección Legal de cartas, dictámenes y otros papeles en Derecho de 1761, pero la mayoría de ellas se perdieron en el terremoto de 1746.

\section{Revolución cultural}

Por su parte, la actual historiadora de la República Carmen Mc Evoy, refiriéndose a los ideales y realidades en la formación de la cultura política peruana, también habla de las «tradiciones en conflicto», planteándose en forma personal las siguientes metas:

- Retomar y continuar la discusión historiográfica sobre la génesis de la burguesía peruana y su proyecto nacional, en la década de 1870 .

- Plantear que cualquier proyecto de construcción estatal va irremisiblemente unido a una revolución cultural que lo legitimiza y avala. Don Ricardo Palma a través de sus tradiciones dará cuenta, en gran parte, de esa revolución cultural que se gestaba ya desde la época de las cuatro últimas gestiones de administración política de los virreyes españoles, haciendo hincapié en las artes escénicas (teatro crítico y costumbrismo) y la literatura (del romanticismo). 
- La autora establece un balance entre crítica y tradición. Partiendo del debate entre los defensores de la teoría crítica y los de la hermenéutica continua, la autora sostiene la revisión de paradigmas a partir del debate entre Jürgen Habermas y Hans-Georg Gadamer, dos posiciones de aproximación a la realidad, que difieren en la metodología, pero que coinciden en rescatar el rol intersubjetivo del lenguaje para el análisis de la sociedad ${ }^{2}$.

- Finalmente, Mc Evoy busca -y lo logra con crecesubicar la historiografía peruana dentro de la historiografía latinoamericana. En el experimento de republicanismo peruano que estudió, el país fue testigo de una profunda fragmentación política que no llevó a una salida violentista como la Revolución Mexicana, ni a una salida electoral como la chilena. «Los fracasos políticos del periodo 1871-1919 [este último es el año en que fallece Ricardo Palma, después de captar, cual radar, los primeros fracasos políticos republicanos] sentaron las bases para el «limbo institucional» y para el lento proceso de deterioro sociopolítico que dura hasta el presente (2017, pp. 49-53).

Un pesimismo irónico recorre casi todas las tradiciones de carácter político de don Ricardo Palma y, tal como lo vemos - en parte- en el presente ensayo, se mantiene hasta el año de su muerte el 6 de octubre de 1919. En todo caso, parafraseando el título de la célebre novela de Gabriel García Márquez debido a la diversidad de investigaciones que aún suscitan sus tradiciones- estamos ante una obra de cien años de solidaridad vigente hasta hoy en día.

2 A propósito véase mi libro sobre Habermas escrito desde la perspectiva peruana, especialmente el capítulo V sobre Acción Comunicativa y Socialización. En: Arista Montoya, L. A. (2004). J. Habermas: Comunicación, Modernidad y Consenso. Lima: Fondo Editorial de la Universidad de San Martín de Porres, p. 197 ss. 
La preocupación y tristeza embargó al viejo maestro en su refugio hogareño de Miraflores. Pues dejaba a un Perú pendiente (muy cerca de la pendiente).

\section{Cuatro meses antes de su muerte,}

El cuatro de julio de 1919 —escribe la autora de La Utopía Republicana, antes citada - la política de lo posible se impuso sobre un ideal cívico-republicano a todas luces inviable. Así, el surgimiento de un experimento político-ideológico alternativo, denominado de la «Patria Nueva» (19191930), sustituyó violentamente al fracaso republicano. Sin embargo, a pesar de su autoproclamada novedad, la «Patria Nueva» no pudo disimular su inocultable aire de familia con el patrimonialismo autoritario que modeló tempranamente la cultura política peruana. De la misma manera, aquella fue incapaz de prescindir del esquizofrénico discurso republicano-conservador, cuyos símbolos intentó destruir. La situación anterior levantó serias dudas en torno a la administración «regeneradora» del presidente Augusto B. Leguía. Este, en su «Manifiesto a la Nación», luego del golpe de Estado contra José Pardo, siguió defendiendo, en nombre de «la patria», la puesta en marcha de una «democracia efectiva». Sin embargo, el problema fundamental giraba en torno a la impertinente e irresuelta pregunta secular: ¿quiénes serían los actores encargados de llevar a cabo la cada vez más complicada tarea democratizadora? (p. 371)

\section{Carmen Mc Evoy también sostiene en su Epílogo que}

Los ideales republicanos de democracia y ciudadanía, entendida esta última como una estrecha conexión con el mundo de la producción y el trabajo [«mundo sistémico», Habermas dixit] fueron dejados de lado en aras del espejismo de la «Patria Nueva», pero es posible encontrar 
ciertos conceptos del republicanismo cívico en las ideologías contestatarias al nuevo modelo político-ideológico implementado por Leguía..., tales como las que surgieron potencializadas en tiendas apristas y socialistas (p. 377)

Hay que decir claramente, acota la historiadora, que

Ser libres nos costó muchísimo y es por ese motivo que en este camino al Bicentenario [año 2021] deberíamos analizar el tema de la libertad, que demanda esfuerzo pero también una responsabilidad personal de la que muchos de los peruanos, hoy presos o esperando entrar a la cárcel por robarnos a mano armada, simplemente carecen (p. 32).

Como se sabe, don Ricardo Palma murió en forma apaciguada, por lo que terminemos con una cita de su hija Angélica Palma:

Cerró los ojos, tranquilo; al poco rato le oí suspirar profundamente, de una manera extraña; corrimos todos a rodear su lecho; su vida terrena había terminado el 6 de octubre de $1919 \ldots$ fue para gloria de su nombre, un literato; para el Perú, un ciudadano; para la vida, un hombre. (1932, p. 124).

Eligió el siguiente «epitafio burlón que él imaginó debía llevar su tumba»:

Aquí yace un peruano escribidor

que ni fue coronel ni fue doctor...

Con esa frase irónica marcó indeleblemente su vida terrenal uno de los escritores peruanos que mejor expresó quínicamente (a través de una razón irónica crítica) el tenso sentimiento trágico entre la vida colonial tardía/vida republicana incipiente. 


\section{Referencias bibliográficas}

Palma, R. (1996). Tradiciones Peruanas. Tomos 1 y 2. Lima: Universidad Ricardo Palma y diario La República.

Palma, A. (1932). Palma. Lima: Editorial Castrillón Silva S.A.

Basadre, J. (1983). Historia de la República (1822-1933). Tomo I. Lima: Editorial Universitaria de Lima.

Valcárcel, C. D. (1985). Breve Historia del Perú. Caracas: Academia Nacional de Historia; Italgráfica S.R.L.

Valcárcel, C. D. (2014). «Rebelión de Juan Santos Atahualpa». En: Cultura Peruana. Manual de Lectura, lera edición. Lima: Universidad Católica Sedes Sapientiae. Área de Historia. Recuperado de https://issuu.com/sprnzpntj/docs/manual_de_lecturas_cultura_ peruana_?cv $=1$

De Ávila, F. (2012). Dioses y Hombres de Huarochirí. Traducción castellana de José María Arguedas. Lima: Instituto de Estudios Peruanos.

Macera, P. (2014). Obras Escogidas de Historia. Lima: Fondo Editorial del Congreso del Perú.

MC. Evoy, C. (2017). La Utopía Republicana. Lima: Fondo Editorial del Congreso.

MC. Evoy, C. (2019). «La república agraviada». En: Diario El Comercio, Lima 19 de mayo. Recuperado de https://elcomercio.pe/opinion/columnistas/ republica-agraviada-carmen-mcevoy-noticia-636545-noticia/

Sloterdijk, P. (2003). Crítica de la razón cínica. Traducción del alemán: Miguel Ángel Vega Madrid: Editorial Siruela. 
